\title{
An Analysis on the Phenomenon of Eng- lish Elision and Its Formation
}

\author{
MA Li-hua
}

Foreign Languages School, Zhejiang Ocean University, Zhoushan 316000, China

\begin{abstract}
As a common phenomenon in human language, elision is of great significance to language learners. This essay explores the phonological rules concerning elision and presents the array of elision phenomena and their constraints on both vowels and consonants, hoping it help learners to acquire English phonetics better.
\end{abstract}

Keywords: Principle of Least Effort; spoken chain; contextual elision

\section{Introduction}

It is evident that in real life English, the pronunciation is more than a simple combination of clearly spoken words. Instead, a flow of spoken chains are pronounced by the speaker accompanied with distinct phonetic changes, including assimilations, elisions, liaison, etc. If a non-native English learner intends to speak fluent and authentic English, he must first master the standard pronunciations of the 46 phonemes of English, and then have a good command of the phonological rule of the language, with special attentions paid to the laws of phonetic change, which occur frequently in fast spoken chains of spoken English. The phenomenon of phonetic change exists in every language and embodies different laws and features in each of them, which explains why it is difficult to truly master a foreign language. Elision is one typical manifestation of phonetic changes. This article en- quires into the limiting conditions of the usage of elision and its formation. Through revealing the general laws of elision, this article will help language learners better get hold of a fluent and authentic English pronunciation.

\section{Description of the phenomenon of elision}

Pronunciation of a language is the material carrier of its meaning. The existence of a language is manifested through the sounds. Therefore when elision occurs in certain speeches, patterns and rules can surely be found. In the following discussions, the article will describe and generalize the phenomenon of elision to acquire some rules of regularity. The elision of vowels, consonants and syllables are observed as follows:

\subsection{Elision of vowels}

\subsection{1. $[\mathcal{H}]$ and [๑] in unstressed syl- lables]}

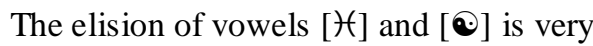
common, which is shown in the pronunciations of the underlined letters in the words below.

temperature

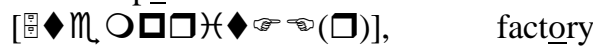
[圆メ甘\&田], business

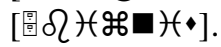

This use of elision is by no means random. It only applies when the mispronounced vowel is in unstressed syllables between two consonants. 


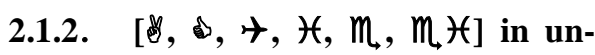
stressed syllables

The pronunciation of these strong vowels in unstressed syllables are weakened and replaced by [๑], a less articulate central vowel. The examples are as follows:

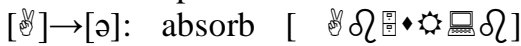

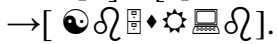

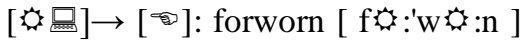
$\rightarrow[\times \odot \square$

$[\uparrow:] \rightarrow[\odot]:$ but $[\delta \leftrightarrow \diamond] \rightarrow$ $[\delta \odot$ ].

$[H] \rightarrow[\odot]:$ benefit [' $\rightarrow m \boldsymbol{\square})\left(x^{\top}\right)(\bullet]$ $\rightarrow\left[' \Omega m \nabla \odot x^{\top}\right)(\bullet]$.

$[\mathrm{m}] \rightarrow$ [๑]:

policeman

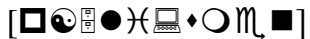

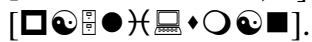

$[\mathrm{m}) \mathrm{H}] \rightarrow \quad[\odot]: \quad$ decade

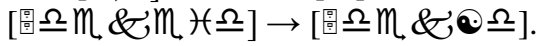

\subsubsection{Diphthong}

In American spoken English, especially in fast speeches, diphthongs are simplified into monophthongs, which mean single vowels, by usually omitting the second sound.

$[m, t] \rightarrow[m]:$ say $[\bullet m) *[\rightarrow[\bullet]$.

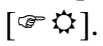

$[\diamond \odot] \rightarrow[\bullet]:$ sure $[\odot \diamond] \rightarrow$ $[\odot \diamond] \rightarrow \quad[\leftrightarrow]: \quad$ problem

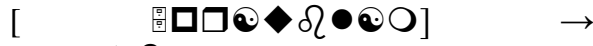

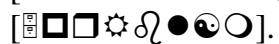

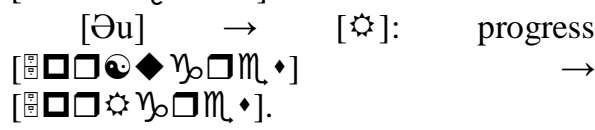

It's worth mentioning that in modern spoken English, the compound vowel

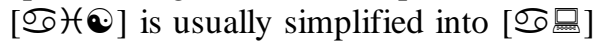
in words such as hire, fire, wire, etc.

\subsection{Elision of consonants}

Below is a list of typical elisions of consonants
Letter b: usually in the form of "mb", "-bt", lamb thumb, subtle, doubt.

Letter c: indicter [ $(\boldsymbol{\square}$ 圆 $\underline{\sigma} \boldsymbol{\theta}(\diamond \odot$ ], $\operatorname{czar}[$ H

Letter $\mathrm{d}$ : Wednesday

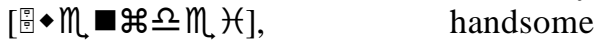

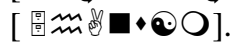

Letter g: usually in the form of "-gn“, gnosis [

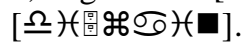

Letter $\mathrm{h}$ : when is the initial letter or in the form of "gh" or after "ex-",

honest [ ghost [ $\left.\eta_{\diamond} \odot \bullet \bullet\right]$, ghetto [ 圆り $m \diamond \odot \diamond]$,

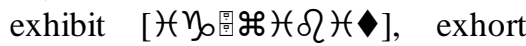

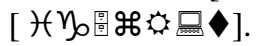

Letter k: know $[\mathbf{\bullet}$ ], knee

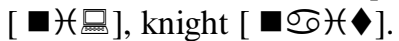

Letter 1: palm [ $\square$ है

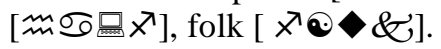

Letter $\mathrm{m}$ : in the form of "mn",

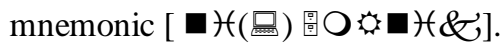

Letter $\mathrm{n}$ : in the form of "mn":

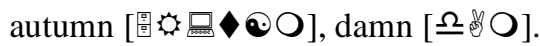

Letter $\mathrm{p}$ : psychology

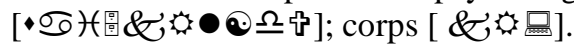

Letter s: aisle [б) $(\bullet]$, island $[$ 圆б) $(\bullet \odot \Omega]$.

Letter $\mathrm{t}$ : nestle [圆m・・], fasten

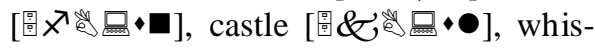
tle $[\bullet)(\square \bullet \bullet]$.

Letter w: in the form of "wr-" and others, wrong $[\square \propto]$, write $[\bullet \square \sigma)(\bullet]$, answer [圆

In the elision of consonants, two typical cases should be paid special attention to:

\subsection{1. [t] and [d]}

These are the two most common consonants in elision. The presence of other plosives, affricates or fricatives in a speech always affects the pronunciation of these two phonemes and results in an incomplete plosion of sounds, such as in: 
Strict parents, bridegroom, hot chocolate.

When pronouncing the underlined letters above, the speaker does not aspirate, so the air-flow in the mouth will not be off-glided, leaving behind a silent, quick pause. Elision of $\mathrm{t}$ or $\mathrm{d}$ between two consonants is very common and known as the simplification of consonant clusters, examples are as follow:

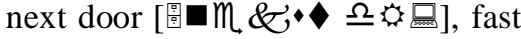

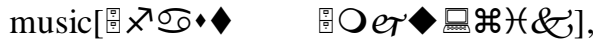 sound track $[\bullet \bullet \mathbf{\sigma}(\Omega)$ 圆 $\square$ \& $\&]$.}

\subsection{2. [h]}

Elision of letter $\mathrm{h}$ is becoming increasingly common and very likely to appear in every phoneme later, especially in quick conversations or when the letter appears at the head of unstressed syllables. Here are the examples:

Give him a book. [ 圖 $\Omega \diamond \&]$.

Did he win? [ $\Omega)(\Omega)(\underline{\square} \cdot)(\mathbf{\square}]$. You`ve met her. [圆er品 OM ๑].

\subsection{Elision of semivowel [j]}

In American English, [eT?四] is sometimes replaced by [↔皿], for example:

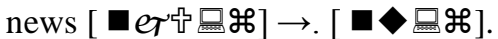

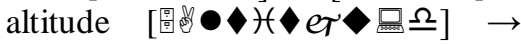

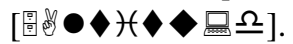

\subsection{Omission of syllables}

The elision of vowels often results in the omission of syllables. And sometimes in informal English, omission of an entire syllable can occur. For example, "because" is simplified into "cus" and pronounced as [\&广म̈], "ecology" is simplified into "eco" and pronounced as

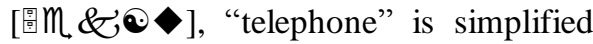
into "phone". Using word-formation methods through elision and omission, similar simplified words such as ad, exam, have changed from informal to formal words and are now included in dictionaries

To sum up, the universality of elision is well recognized in the pronunciations of vowels, consonants as well as the entire syllables. Referring to the diachronic and synchronic characteristics of the variations of pronunciations, a number of phonetists classify different elisions into two major categories: historical elision and contextual elision. Historical elision is formed with the evolution of history, the rule of which is fixed as English develops and is not influenced by subjective linguistic or behavioral factors. Therefore whenever the conditions hold, relevant elision will mandatorily occurs. Contextual elision, on the other hand, is formed in continuous spoken chains according to adjacent phonemes as well as the speed, tone and volume of the speech. Dependence on the speed and randomness of the speech implies that the elision is optional for the speaker. We can summarize the above ideas into the following chart:

\begin{tabular}{|c|c|c|c|}
\hline \multicolumn{2}{|c|}{ Types of elision } & Example & $\begin{array}{l}\text { Pronuncia- } \\
\text { tion }\end{array}$ \\
\hline \multirow{2}{*}{$\begin{array}{l}\text { Elision of } \\
\text { vowels }\end{array}$} & $\begin{array}{l}\text { Historical } \\
\text { elision }\end{array}$ & $\begin{array}{l}\mathrm{e} \text { in eu- } \\
\text { phemism }\end{array}$ & 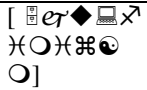 \\
\hline & $\begin{array}{l}\text { Contextu- } \\
\text { al elision }\end{array}$ & $\begin{array}{l}\mathrm{o} \text { in victo- } \\
\text { ry }\end{array}$ & $\begin{array}{l}{[\text { 圖\& }} \\
\odot \square)(\text { ] }\end{array}$ \\
\hline \multirow{2}{*}{$\begin{array}{l}\text { Elision of } \\
\text { conso- } \\
\text { nants }\end{array}$} & $\begin{array}{l}\text { Historical } \\
\text { elision }\end{array}$ & $\begin{array}{l}\text { gh in } \\
\text { bright }\end{array}$ & 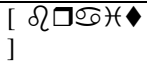 \\
\hline & $\begin{array}{l}\text { Contextu- } \\
\text { al elision }\end{array}$ & $\begin{array}{l}\mathrm{t} \text { in most- } \\
\mathrm{ly}\end{array}$ & $\begin{array}{l}\text { [圖○○ } \\
\text { f] } .\end{array}$ \\
\hline \multirow{2}{*}{$\begin{array}{l}\text { Elision of } \\
\text { syllables }\end{array}$} & $\begin{array}{l}\text { Historical } \\
\text { elision }\end{array}$ & I & / \\
\hline & $\begin{array}{l}\text { Contextu- } \\
\text { al elision }\end{array}$ & $\begin{array}{l}\text { be in be- } \\
\text { cause }\end{array}$ & [\&○भ] \\
\hline
\end{tabular}

\section{An inquiry into causes of formation}

The principle of least effort is a common law governing human behavior. In similarity with other human actions, evolution of a language aims at being more economical and expedient; its development tends to gradually adopt easier language forms to replace difficult ones. A typcal 
case: ancient English words like "hlaf", "hring", and "hit" evolved into "loaf", "ring" and "it" caused by the disappearance of the first letter " $h$ " during the language's transformation into a modern one. In comparison, it's much more energyconsuming to pronounce the words' old version correctly. Another example involves the abundant usage of abbreviations in modern English, such as flu from influenza and fridge from refrigerator. Elision phenomenon like incomplete plosion also demonstrates such energysaving principle: due to its powerful amplitude, which makes it harder for human vocal organs to pronounce two adjacent plosives, the former one loses part or all of its plosion. This kind of elision takes place in other consonant clusters too.

Apart from the principle of least effort, other causes may also account for elision in English:

\subsection{The Phonological rules of English}

Pursuant to the "concord principle" in English morphology, when two or more phonemes are completely or partly identical in distinctive features, one of them is likely to be omitted. Relative to vowels, consonants have similar distinctive features, which lead to the elision of one consonant when a consecution of them appears in a flow of speech, for instance:

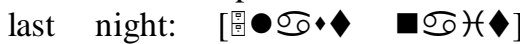
$\rightarrow[$ 可 $(\diamond) \square \sigma)(\downarrow],[\mathrm{t}]$ is omitted from the consonant cluster $[\bullet \boldsymbol{\bullet}]$; extraordinary:

[H\&圈・穴

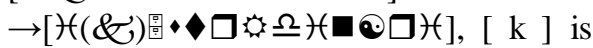
omitted from the consonant cluster $[\& \bullet \bullet \square]$;

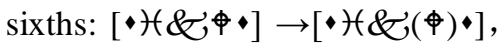

$[\phi]$ is omitted from the consonant cluster [\&束; mostly:

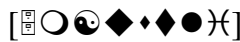

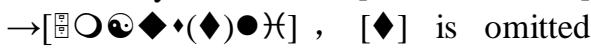
from the consonant cluster $[\bullet \bullet \bullet]$.
It has become common to avoid or omit complicated consonant clusters in pronunciation, and its odds prove to be higher when two consonants have more overlapping distinctive features. Elision is almost inevitable to occur in common consonant clusters like "-mm-“, "-mb”, “gh-", not only because of their identical prime attributes (consonant), but also of their identical characteristics in acoustic cavity: both $\mathrm{m}$ and $\mathrm{n}$ are nasal sounds, $\mathrm{m}$ and $\mathrm{b}$ bilabials, and $\mathrm{g}$ and $\mathrm{h}$ non-front sounds, albeit their difference in place and method of articulation.

\subsection{The necessity of phonetic balance and cadence.}

English is a typical stress-timed language. The appearance of stressed syllables is regular, with almost the same time interval. Unstressed syllables are usually omitted in order to achieve phonetic balance and a sense of rhyme. Traditional poetry emphasizes immaculate metrical pattern and therefore would adopt lots of elision for the sake of rhyme. Modern poetry has inherited such trait. The following is an excerpt from an English song where "got to", "going to" and "want to" take on their colloquial form "gotta", "gonna", "wanna" and has omitted two plosives, which in turn enhances the brevity, rhyme and symmetry of the language.

Sealed with a Kiss

Though we gotta say good bye...

Yes it's gonna be

A cold lonely summer...

But darling you won't be there

I don't wanna say good bye

In common parlance, elision in context is often reflected on the weakened words. For example:

Have you read your book? - [

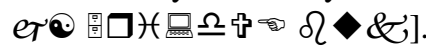

[*] and [eT॰] are the weakened form of have and you, which serves to balance phonetics and rhyme. 


\subsection{The influence of borrowed words}

The words with monograms like"ae", "eu"'oe"are of Latin origin and their first syllable is omitted in pronunciation because there's no such phoneme permutation in English, such as:

aesthetics

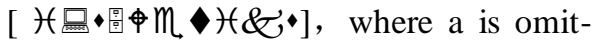
ted;

euphemism

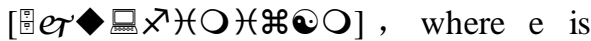
omitted.

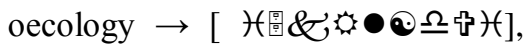
where $\mathrm{o}$ is omitted.

In another opposite situation, borrowed languages prescribe the elision of certain syllables which shouldn't in accord with English rules in pronunciation but are still preserved to protect its authenticity, as the last consonant of French words usually stays unpronounced, like coup and corps pronounced as [\& and $[\& ; 0]$.

\subsection{The influence of dialects}

The elision of $[\mathcal{e}]$ after gum consonants is under the influence of regional dialects, which mainly appears in American English, such as:

Tune is pronounced as [ $e \boldsymbol{T}$ ] in British accent, but [ ican accent;

sue is pronounced as [ $\bullet \mathcal{T}$ 묘] $]$, but

$[\bullet \square]$ in American accent; new is pronounced as [ $\boldsymbol{E} \tau$ 品], but [ $\bullet$ 믐] in American accent.

\section{Final thoughts}

Elision takes form under certain rules of pronunciations and subjects to the influence of time, location and other different factors. Except for historical elision, most elisions are random and variable, sometimes even lack of unified forms. But the habitual and systematic features of the phenomenon of elision indicate that there are patterns to follow. This article mainly focuses on the description and preliminary generalization of the phenomenon of elision and touches on its causes of formation. And there remain many elements to be further examined and discussed to learn more about the complexity of this subject.

\section{References}

[1] Jones, D. An Outline of English Phonetics $[\mathrm{M}]$. Cambridge University Press. 1976.

[2] Meng xianzhong. English Phonetics $[\mathrm{M}]$.Huazhong Normal University Press. 2003.

[3] R. H. Robins, General Linguistics [M] Foreign Language Teaching and Research Press, 2000

[4] Dai weidong. Introduction to modern English linguistics $[M]$. Shanghai Foreign Language Education Press.1998.

[5] Hornby,A.S. Oxford Advanced learner' Dictionary of Current English [M]. Oxford University Press. 1989. 